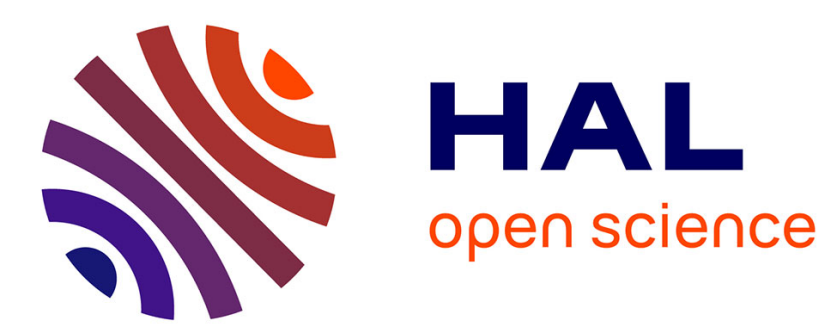

\title{
Metadislocations in the orthorhombic structurally complex alloy $\mathrm{Al} 13 \mathrm{Co} 4$
}

\author{
Marc Heggen, Lothar Houben, M. Feuerbacher
}

\section{To cite this version:}

Marc Heggen, Lothar Houben, M. Feuerbacher. Metadislocations in the orthorhombic structurally complex alloy Al13Co4. Philosophical Magazine, 2008, 88 (13-15), pp.2333-2338. 10.1080/14786430802132530 . hal-00513897

\section{HAL Id: hal-00513897 \\ https://hal.science/hal-00513897}

Submitted on 1 Sep 2010

HAL is a multi-disciplinary open access archive for the deposit and dissemination of scientific research documents, whether they are published or not. The documents may come from teaching and research institutions in France or abroad, or from public or private research centers.
L'archive ouverte pluridisciplinaire HAL, est destinée au dépôt et à la diffusion de documents scientifiques de niveau recherche, publiés ou non, émanant des établissements d'enseignement et de recherche français ou étrangers, des laboratoires publics ou privés. 


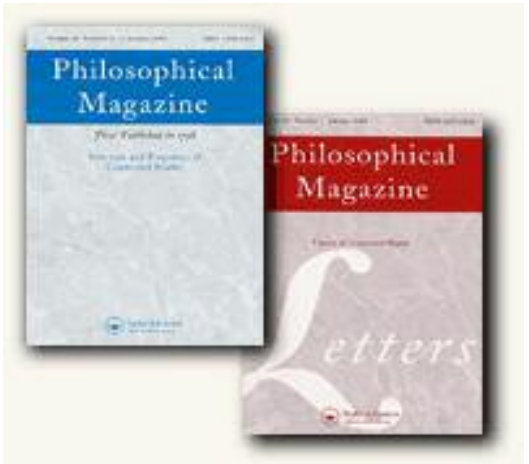

Metadislocations in the orthorhombic structurally complex alloy Al13Co4

\begin{tabular}{|c|c|}
\hline Journal: & Philosophical Magazine \& Philosophical Magazine Letters \\
\hline Manuscript ID: & TPHM-07-Oct-0274.R2 \\
\hline Journal Selection: & Philosophical Magazine \\
\hline $\begin{array}{r}\text { Date Submitted by the } \\
\text { Author: }\end{array}$ & $25-F e b-2008$ \\
\hline Complete List of Authors: & $\begin{array}{l}\text { Heggen, Marc; Forschungszentrum Juelich } \mathrm{GmbH} \text {, Institut fuer } \\
\text { Festkoerperforschung } \\
\text { Houben, Lothar; Forschungszentrum Juelich GmbH, Institut fuer } \\
\text { Festkoerperforschung } \\
\text { Feuerbacher, M.; Forschungszentrum Jülich, Institut für } \\
\text { Festkörperforschung }\end{array}$ \\
\hline Keywords: & dislocation structures, phase changes, plasticity, TEM \\
\hline Keywords (user supplied): & complex metallic alloys, metadislocation \\
\hline
\end{tabular}

\section{S) ScholaroNE" Manuscript Central}




\title{
Metadislocations in the orthorhombic structurally complex alloy $\mathrm{Al}_{13} \mathrm{Co}_{4}$
}

\author{
Marc Heggen, Lothar Houben, Michael Feuerbacher \\ Institut für Festkörperforschung, Forschungszentrum Jülich GmbH, \\ D-52425 Jülich, Germany
}

\begin{abstract}
Recently, the existence of metadislocations in the orthorhombic complex metallic phase $\mathrm{Al}_{13} \mathrm{Co}_{4}$ was postulated (M. Feuerbacher, M. Heggen, (2006), Phil. Mag. 86, 985). The present work is a microstructural characterization of defects in this phase by means of transmission electron microscopy. A dislocation core region and associated planar defects were investigated in a plastically deformed sample. The planar defects were shown to be $\left(\begin{array}{lll}0 & 0 & 1\end{array}\right)$ slabs of a monoclinic phase in the orthorhombic $\mathrm{Al}_{13} \mathrm{Co}_{4}$ matrix. Microstructural investigations reveal the presence of an edge dislocation. The strain at the dislocation core is partially compensated by the introduction of the monoclinic phase. A structural model of the core region based on a tiling description is developed. The Burgers vector of the dislocation yields - $2.9 \AA\left[\begin{array}{lll}0 & 1 & 0\end{array}\right]$, which is a small irrational fraction of the lattice constant. A comparison with metadislocations and dislocations in Laves phases is made, and a definition of a metadislocation including metadislocation glide is made.
\end{abstract}




\section{$\S 1$. Introduction}

Metadislocations are novel defects in complex metallic alloys (CMAs) and were firstly observed in the phases $\xi^{\prime}$ - and $\psi-\mathrm{Al}-\mathrm{Pd}-\mathrm{Mn}[1]$, and more recently in $\xi-\mathrm{Al}-\mathrm{Pd}-\mathrm{Fe}$ [2]. The core of a metadislocation is a line defect which ideally extends along the $\left[\begin{array}{lll}0 & 1 & 0\end{array}\right]$ direction of the $\xi^{\prime}$-phase lattice. It is associated to a certain number of planar defects, so-called phason planes, which are ideally $\left(\begin{array}{lll}0 & 0 & 1\end{array}\right)$ oriented. The existence of metadislocations in other groups of CMAs, which are not isostructural or directly structurally related to $\xi^{\prime}$ - and $\psi-\mathrm{Al}-\mathrm{Pd}-\mathrm{Mn}$, was proposed [3]. One of these phases is the orthorhombic phase $\mathrm{Al}_{13} \mathrm{Co}_{4}$.

In a previous work on single crystalline $\mathrm{o}-\mathrm{Al}_{13} \mathrm{Co}_{4}$ plastic deformation experiments and microstructural investigations were performed by means of transmission electron microscopy (TEM) [4]. These investigations on plastically deformed samples revealed a high density of [1 0 0] dislocations terminating ( $\left.\begin{array}{lll}0 & 0 & 1\end{array}\right)$ planar defects. Contrast-extinction experiments disclosed that the Burgers vectors of dislocations and the displacement vector of the associated planar defects are parallel to the $\left[\begin{array}{lll}0 & 1 & 0\end{array}\right]$ direction. It was concluded that dislocation glide on $\left(\begin{array}{lll}0 & 0 & 1\end{array}\right)$ planes is the basic mechanism of plastic deformation.

Here, we present a more detailed microstructural investigation on the structure of dislocations in $\mathrm{o}-\mathrm{Al}_{13} \mathrm{Co}_{4}$ by means of scanning transmission electron microscopy (STEM) and TEM. The microstructural investigation aims at a comparison with the structure of metadislocations. Results on the basis of a tiling approach are discussed.

\section{$\S 2$. The structure of $\mathrm{Al}_{13} \mathrm{Co}_{4}$}

$\mathrm{Al}_{13} \mathrm{Co}_{4}$ is an orthorhombic phase (denoted o- $\mathrm{Al}_{13} \mathrm{Co}_{4}$ ) with space group $\mathrm{Pmn} 2_{1}$ and lattice parameters $a=8.2 \AA, b=12.3 \AA$, and $c=14.5 \AA$ [5,6]. Structure investigations were performed by several groups [e.g. 6,7]. The main structural feature of o- $\mathrm{Al}_{13} \mathrm{Co}_{4}$ are pair-connected pentagonal prismatic channels extending along the $\left[\begin{array}{lll}1 & 0 & 0\end{array}\right]$ direction [6]. Within the (1 00 ) plane, the o- $\mathrm{Al}_{13} \mathrm{Co}_{4}$ structure can be matched by a tiling consisting of regular pentagons and rhombs [8], depicted in figure 1 a. The edges of the tiles correspond to atomic columns, which are predominately occupied by cobalt atoms. The orthorhombic unit cell is superimposed onto the tiling.

The structure of monoclinic phase m- $\mathrm{Al}_{13} \mathrm{Co}_{4}$ is homeotypic to that of monoclinic $\mathrm{Al}_{13} \mathrm{Fe}_{4}$, and 
structurally closely related to $\mathrm{o}-\mathrm{Al}_{13} \mathrm{Co}_{4}[6,7,8,9,10]$. The tiling description of $\mathrm{m}-\mathrm{Al}_{13} \mathrm{Co}_{4}$ (figure $1 \mathrm{~b})$ is characterized by a parallel arrangement of the pentagon and rhomb elements.

In order to compare both tilings a cubic basis using the edge length of the tiles $(4.7 \AA)$ is used in the remainder of this paper. In terms of this basis the $\left(\begin{array}{lll}1 & 0 & 0\end{array}\right)$ projection of the orthorhombic cell is spanned by the vectors $\left(\begin{array}{lll}\tau+1 & 0\end{array}\right)$ and $\left(\begin{array}{ll}0 & \tau \sqrt{\tau+2}\end{array}\right)$ and that of the monoclinic cell by $(\tau+1$ 0 ) and (1 $\tau \sqrt{\tau+2}$ ), where $\tau=\frac{\sqrt{5}+1}{2}$ is the number of the golden mean.

\section{$\S$ 3. Experimental}

$\mathrm{Al}_{13} \mathrm{Co}_{4}$ single grains of the order of 1 to $2 \mathrm{~cm}^{3}$ were grown by means of the Bridgman technique. The quality of the material was characterized by means of phase-contrast optical microscopy, scanning electron microscopy, and TEM. Cuboid shaped samples were plastically deformed using a modified Zwick Z050 testing machine in uniaxial compression at constant strain rate of $10^{-5} \mathrm{~s}^{-1}$. Samples were deformed at $650{ }^{\circ} \mathrm{C}$ and $800{ }^{\circ} \mathrm{C}$ to about $6 \%$ strain. After deformation, the samples were rapidly unloaded, quenched on a cold metal plate to preserve their microstructural state, and prepared for TEM. The microstructural investigations were carried out using a JEOL 4000EX transmission electron microscope and a FEI TITAN 80-300 transmission electron microscope equipped with an aberration corrector for the probe-forming lens. Highangle annular dark-field (HAADF) images were taken at $300 \mathrm{kV}$ at a probe semiangle of $25 \mathrm{mrad}$ and a detector inner collection angle of $70 \mathrm{mrad}$.

\section{$\S$ 4. Microstructural investigation}

Figure 2 shows a HAADF micrograph of a deformed $\mathrm{Al}_{13} \mathrm{Co}_{4}$ sample along the $\left[\begin{array}{lll}1 & 0 & 0\end{array}\right]$ direction. Bright dots in the micrograph correspond to atomic columns which are preferentially occupied by cobalt atoms. They can be matched by the $\mathrm{o}-\mathrm{Al}_{13} \mathrm{Co}_{4}$ tiling. Columns occupied by aluminium are not visible. We have imaged stacking faults with $\left(\begin{array}{lll}0 & 0 & 1\end{array}\right)$ fault plane in edge-on orientation (marked by arrows). They are not conventional planar defects involving a displacement at a sharp interface, but structurally modified slabs of nanometre thickness. The structure within the slabs can be matched by a tiling corresponding to the $\mathrm{m}-\mathrm{Al}_{13} \mathrm{Co}_{4}$ rather than that of the $\mathrm{o}-\mathrm{Al}_{13} \mathrm{Co}_{4}$ phase. 
Figure 3 shows a high-resolution TEM micrograph of a dislocation (central part of the image) in end-on orientation. The dislocation terminates a $\left(\begin{array}{lll}0 & 0 & 1\end{array}\right)$ planar defect, i.e. a structurally modified slab of $\mathrm{m}-\mathrm{Al}_{13} \mathrm{Co}_{4}$, extending to the right-hand side of the image. The outline of the o$\mathrm{Al}_{13} \mathrm{Co}_{4}$ unit cells is depicted by white rectangles, which can be used to cover the undistorted o$\mathrm{Al}_{13} \mathrm{Co}_{4}$ crystal regions. Rhomboids representing the unit cell of the monoclinic $\mathrm{Al}_{13} \mathrm{Co}_{4} \mathrm{phase}$ are used to cover the structurally modified slab. Analysing the structure around the dislocation core region, the micrograph clearly shows the presence of three unit cells of o- $\mathrm{Al}_{13} \mathrm{Co}_{4}$ directly above the dislocation core and two unit cells below the dislocation core, i.e. one additional ( $\left.\begin{array}{lll}0 & 1 & 0\end{array}\right)$ half plane, extending to the upper region of the image, is inserted at the dislocation core. The defect displayed in Figure 3 represents a typical dislocation, terminating a planar defect in deformed $\mathrm{Al}_{13} \mathrm{Co}_{4}$. Similar dislocations, which can be described using the same arrangement of rectangular and rhomboidal structural elements have been observed at a high density.

\section{§. Discussion}

The present investigation reveals structural information on dislocation cores and associated planar defects in deformed $\mathrm{Al}_{13} \mathrm{Co}_{4}$. The planar defects are not conventional stacking faults, but slabs of the $\mathrm{m}-\mathrm{Al}_{13} \mathrm{Co}_{4}$ phase. Plastic deformation is associated to a mechanism involving a structural transformations from the $\mathrm{o}-\mathrm{Al}_{13} \mathrm{Co}_{4}$ to the $\mathrm{m}-\mathrm{Al}_{13} \mathrm{Co}_{4}$ structure. The observation of monoclinic slabs in the $\mathrm{o}-\mathrm{Al}_{13} \mathrm{Co}_{4}$ matrix corresponds well to earlier observations where mixtures of structural elements corresponding to monoclinic and orthorhombic phases related to $\mathrm{Al}_{13} \mathrm{Co}_{4}$ were observed. Saito and coworkes [8] identified (llll 0 l 1 1) planar defects in as-cast $\mathrm{Al}_{13} \mathrm{Co}_{4}$ and identified them, by means of high-resolution TEM and X-ray diffraction, as monoclinic slabs in an orthorhombic matrix. Further examples and references on planar defects and twinning in phases which are structurally related to $\mathrm{Al}_{13} \mathrm{Co}_{4}$ are found, e.g., in [11].

Let us analyze the structure of the dislocation in figure 3 in more detail. The tiling description cannot be applied directly to the high-resolution TEM micrograph in the same obvious way like to the HAADF micrograph. However, the configuration of unit cells around the dislocation is clearly observable and will be used to develop a tiling model of the dislocation core. In figure 4 a the tiling for $\mathrm{o}-$ and $\mathrm{m}-\mathrm{Al}_{13} \mathrm{Co}_{4}$ is applied to the lattice structure around the dislocation core. The dark grey polygon represents the core of the dislocation. To match the strained structure, the tiles are slightly distorted around the core. A Burgers circuit is performed around the dislocation core 
(figure 4 a) and transferred to an undistorted tiling (figure $4 \mathrm{~b}$ ). The latter tiling reveals a closure failure and displays the Burgers vector of the dislocation (white arrow). It corresponds to the vector $1 / \tau^{3} 12.3 \AA\left[\begin{array}{lll}0 & 1 & 0\end{array}\right]=2.9 \AA\left[\begin{array}{lll}0 & 1 & 0\end{array}\right]$ in terms of the orthorhombic basis. We note that the determination of the Burgers vector is not dependent on a specific geometric description of the dislocation core in terms of the tiling. The same Burgers vector is determined by performing a Burgers circuit, shown in figure 3, around the dislocation core using the unit cell representation.

The dislocation observed in the present work is an edge dislocation which moves in terms of glide [4]. Upon movement it creates not a conventional stacking fault but a structurally modified slab of the $\mathrm{m}-\mathrm{Al}_{13} \mathrm{Co}_{4}$ phase. The structural transition partially compensates the large lattice distortion of the inserted half plane and yields a Burgers vector which is much smaller than the respective lattice constant. This mechanism resembles shear transformations observed in Laves phases where moving dislocations may introduce structurally modified slabs [12-14]. In the C14 Laves phase $\mathrm{Cr}_{2} \mathrm{Hf}$, for instance, dislocation motion creates a slab of the cubic $\mathrm{C} 15$ Laves phase within the C14 matrix [14].

Furthermore, the dislocations observed in the present work are closely related to metadislocations having the same Burgers vector [3]. The main difference, however, is related to the planar defects associated with them. Metadislocations are necessarily associated to a set of planar defects, so-called phason planes [1]. While the dislocations observed in the present paper are connected to $\left(\begin{array}{lll}0 & 0 & 1\end{array}\right)$ planar defects, the associated phason planes of the proposed metadislocations are $\left(\begin{array}{lll}0 & 1 & 0\end{array}\right)$ planes [3]. Therefore the mode of dislocation motion is different. While metadislocations move by means of pure climb, the present dislocations move by glide.

In conclusion, despite the difference in the mode of dislocation motion, the dislocations observed in the present work show clear similarities with metadislocations. This observation suggests an extension of the term metadislocation to a more general concept including metadislocation glide: A metadislocation is a line defect with a Burgers vector which is a $1 / \tau^{\mathrm{n}}$ fraction $(n=1,2,3, \ldots)$ of the corresponding lattice constant. It is associated with a local phase transformation to a phase which is structurally closely related to the matrix. By this means, the irrational Burgers vector fraction is accommodated to the lattice. The metadislocation core region comprises structural features of both phases. This definition involves the dislocations observed in CMAs $\mathrm{Al}_{13} \mathrm{Co}_{4}$ (this work), $\xi^{\prime}-$ and $\psi-\mathrm{Al}-\mathrm{Pd}-\mathrm{Mn}[1]$, and $\xi-\mathrm{Al}-\mathrm{Pd}-\mathrm{Fe}$ [2]. 


\section{Acknowledgments}

This work was supported by the Deutsche Forschungsgemeinschaft (PAK 36), and the $6^{\text {th }}$ Framework EU Network of Excellence "Complex Metallic Alloys" (Contract No. NMP3-CT2005-500140). 


\section{REFERENCES}

[1] H. Klein, M. Feuerbacher, P. Schall, K. Urban, (1999), Phys. Rev. Lett. 82, 3468.

[2] M. Feuerbacher, S. Balanetskyy, M. Heggen, (2008), Acta. Mater., in press.

[3] M. Feuerbacher, M. Heggen, (2006), Phil. Mag. 86, 985.

[4] M. Heggen, D. Deng, M. Feuerbacher, (2007), Intermetallics 15, 1425.

[5] T. Gödecke, M. Ellner, (1996), Z. Metallkd. 87, 11.

[6] J. Grin, U. Burkhardt, M. Ellner, K. Peters, (1994), J. Alloys \& Comp. 206, 243.

[7] R.C. Hudd, W.H. Tailor, (1962), Acta Cryst. 15, 441.

[8] K. Saito, K. Sugiyama, K. Hiraga, (2000), Mat. Sci. \& Eng. A 294-296, 279.

[9] J. Grin, U. Burkhardt, M. Ellner, K. Peters, (1994), Z. Kristallogr. 209, 479.

[10] B. Grushko, R. Wittenberg, K. Bickmann, C. Freiburg, (1996), J. Alloys \& Comp. 233, 279.

[11] M. Ellner, (1995), Acta Cryst. B 51, 31-36.

[12] C.W. Allen, K.C. Liao, (1982), Phys. Stat. Sol. A 74, 673.

[13] P.M. Hazzledine, P. Pirouz, (1993), Scripta. Met. 28, 1277.

[14] M.F. Chisholm, S. Kumar, P. Hazzledine, (2005), Science 307, 701. 


\section{FIGURE CAPTIONS}

Fig.1 Tiling representation of the orthorhombic (a) and monoclinic (b) $\mathrm{Al}_{13} \mathrm{Co}_{4}$ structure using pentagon and rhomb elements. The unit cells are superimposed to the tilings. A projection of the orthorhombic $\mathrm{Al}_{13} \mathrm{Co}_{4}$ structure according to Ref. [6] is given.

Fig.2 High-angle annular dark field micrograph of a deformed $\mathrm{Al}_{13} \mathrm{Co}_{4}$ sample along the $\left[\begin{array}{lll}1 & 0 & 0\end{array}\right]$ direction. White circles correspond to cobalt columns. Tiling representations are superimposed. Structurally modified slabs corresponding to the $\mathrm{m}-\mathrm{Al}_{13} \mathrm{Co}_{4}$ rather than that of the o- $\mathrm{Al}_{13} \mathrm{Co}_{4}$ phase can be observed (arrows and broken lines).

Fig.3 High-resolution micrograph of a dislocation (centre part of the image) in edge-on orientation terminating a $\left(\begin{array}{lll}0 & 0 & 1\end{array}\right)$ planar defect (right hand side of the image). White rectangles and rhomboids indicate the unit cell of $\mathrm{o}-$ and $\mathrm{m}-\mathrm{Al}_{13} \mathrm{Co}_{4}$.

Fig.4 (a) Structural model of the dislocation in figure 4 in terms of the tiling description. (b) Enlargement of the dislocation core in terms of an unstrained tiling disclosing the Burgers vector (arrow) of the dislocation. 


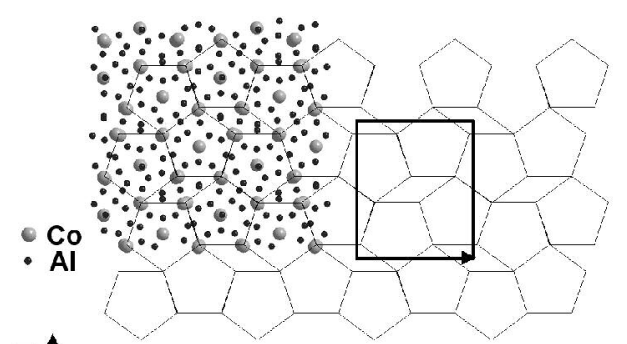

$z \stackrel{\longrightarrow}{\longrightarrow}$ a)

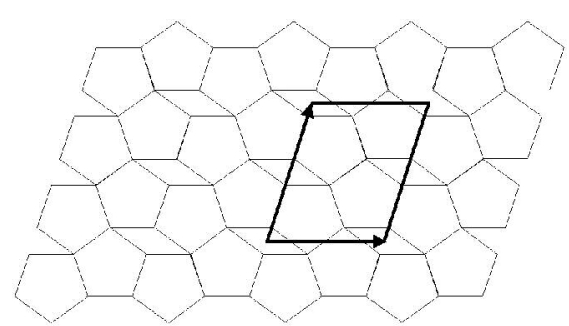

b)

Tiling representation of the orthorhombic (a) and monoclinic (b) Al13Co4 structure using pentagon and rhomb elements. The unit cells are superimposed to the tilings. A projection of the orthorhombic Al13Co4 structure according to Ref. [6] is given. $705 \times 257 \mathrm{~mm}(72 \times 72$ DPI $)$ 


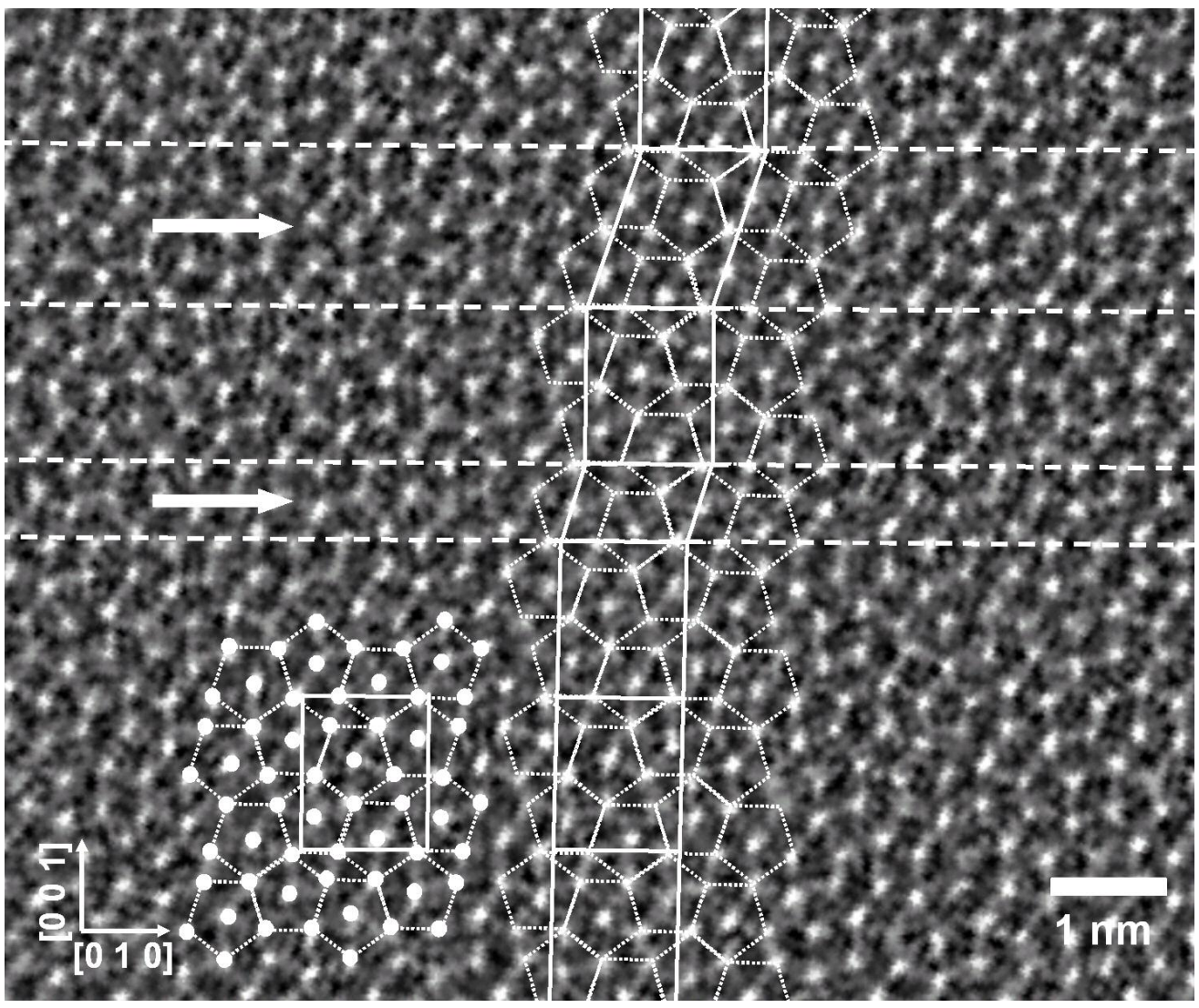

High-angle annular dark field micrograph of a deformed Al13Co4 sample along the [ $\left.\begin{array}{lll}1 & 0 & 0\end{array}\right]$ direction. White circles correspond to cobalt columns. Tiling representations are superimposed. Structurally modified slabs corresponding to the m-Al13Co4 rather than that of the o-Al13Co4 phase can be observed (arrows and broken lines). $521 \times 437 \mathrm{~mm}(72 \times 72 \mathrm{DPI})$ 


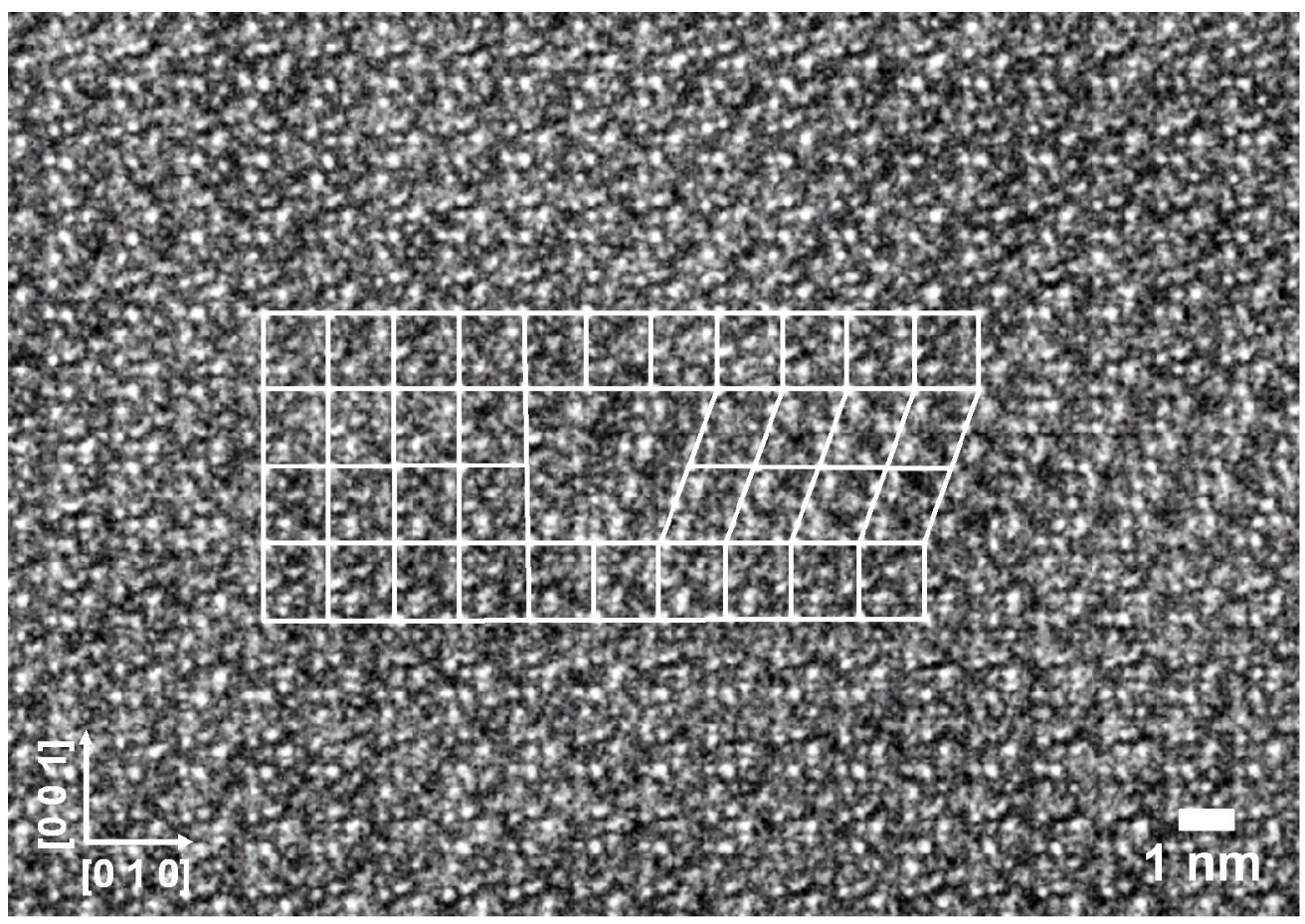

High-resolution micrograph of a dislocation (centre part of the image) in edge-on orientation terminating a ( $\left.\begin{array}{lll}0 & 0 & 1\end{array}\right)$ planar defect (right hand side of the image). White rectangles and rhomboids indicate the unit cell of $0-$ and $\mathrm{m}-\mathrm{Al} 13 \mathrm{Co} 4$. $564 \times 395 \mathrm{~mm}(72 \times 72 \mathrm{DPI})$ 


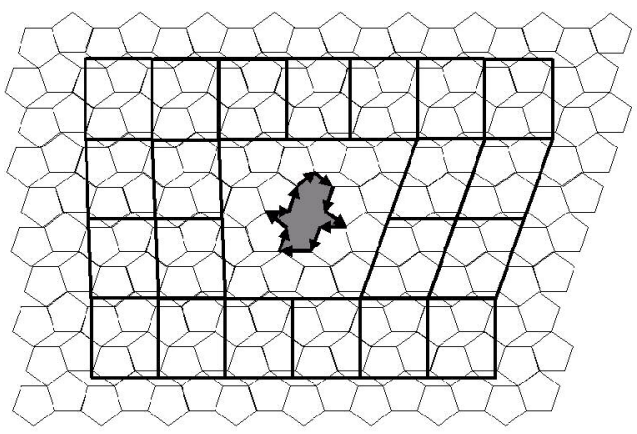

a)

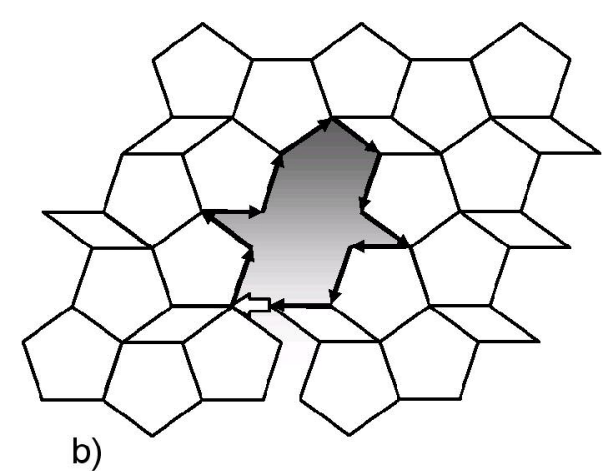

b)

(a) Structural model of the dislocation in figure 4 in terms of the tiling description. (b) Enlargement of the dislocation core in terms of an unstrained tiling disclosing the Burgers vector (arrow) of the dislocation. $564 \times 204 \mathrm{~mm}(72 \times 72$ DPI $)$ 